\title{
PERENCANAAN SISTEM PENYEDIA AIR BERSIH IKK KARANGBINANGUN
}

\author{
Sholeh $^{1}$, Nur Azizah Affandy ${ }^{2}$ \\ ${ }^{1}$ Program Studi Teknik Sipil Fakultas Teknik Universitas Islam Lamongan \\ ${ }^{2}$ Program Studi Teknik Sipil Universitas Islam Lamongan \\ email: sholehcelloaditia@gmail.com,nurazizah_5@yahoo.com
}

\begin{abstract}
Water is a basic human need. The effect of water is vast for life, especially water for cooking and drinking. Karangbinangun district does not yet have a good and clean water supply network system. In the effort to provide clean water, distribution network is important. Because this distribution network that distributes from production installation to the community. The purpose of this research is to know the planning of clean and good network system for Karangbinangun district and To know the average amount of water demand needed by the people of Karangbinangun district in the next 10 (ten) years. The research methods using two methods, namely data collection technique, and data analysis technique. Data collection technique was conducted with primary survey and secondary survey. As for data analysis processed using the relevant empirical formula, without changing the authenticity of data. Prediction of population In Karangbinangun district in 2026 is 17420. And from the calculation of planning can be known service of clean water requirement in Karangbinangun district in year projection 2026 minimum required debit is 1,443,818,38 lt / hr or 60,159,10 lt / jm =1,002.65 lt / mnt $=16,71 \mathrm{lt} / \mathrm{dt}=0.02$ $\mathrm{m} 3 / \mathrm{s}$. From the calculation result is known pipe diameter of $150 \mathrm{~mm}$, and pump spesification $Q$ $=16,71 \mathrm{lt} / \mathrm{dt}$ and Head of $27,9 \mathrm{~m}$ or $30 \mathrm{~m}$, for planning of water supply system IKK Karangbinangun.
\end{abstract}

Keywords : Distribution, Clean Water, Population, Pipe Network.

\section{PENDAHULUAN}

Pelalayan kebutuhan air bersih di Kecamatan Karangbinangun rata-rata dilayani secara mandiri yaitu menggunakan sumur bor. Kedalamman sumur bumur bor yang digunakan antara 80-90 m. kedalaman pipa suction pompa rata-rata 2 lonjor (8 meter). Pada musim kemarau sumur yang digunakan penduduk masih ada namun mengalami penurunan kapasitas. Kebutuuhan untuk mencuci dan mandi menggunakan air dari sumur bor ini, sedangkan untuk keperluan minum membeli galonan atau isi ulanng. Masyarakat membeli air jurigen kepada penjual dengan rata-rata Rp. 10.000/6 jurigen untuk keperluan minum dan masak.

Pada Kecamatan Karangbinangun terdapat jaringan perdesaan yaitu dari PU dan WSLIC. Terdapat 13 desa yang memiliki jaringan perdesaan, kondisi jaringan perdesaan tersebut dalam kondisi baik dan masih beroperasi.
Kebutuhan air baku rata-rata dari bengawan solo dan embung-embung yang ada.

Kecamatan Karangbinangun dilewati oleh kali Blawi, namun pada musim kemarau mengalami kekeringan. Sebelum dibangun bendung gerak sembayat, Bengawan solo yang melintas Kecamatan Karangbinangunn pada musim kemarau mengalami intrusi air laut terutama di Desa Banjarejo, putatbangah, dan Watangpanjang.

Jumlah penduduk di Kecamatan Karangbinangun berdasarkan data BPS Tahun 2015 adalah 41.286 jiwa, desa yang mempunyai penduduk terbanyak adalah Desa Mayong dengan jumlah penduduk 3.530 jiwa, sedangkan yang mempunyai penududuk terkecil adalah Desa Priyoso dengan penduduk sebanyak 888 jiwa.

Dalam upaya penyediaan air bersih, jaringan distribusi merupakan hal penting. Karena jaringan distribusi inilah yang 
menyalurkan dari intalasi produksi ke masyarakat.

Kecamatan karangbinangun belum memiliki sistem jaringan air bersih yang baik dan memadahi. Dari hal-hal tersebut diatas maka perlu adanya perencanaan pengembangan jaringan distribusi air bersih PDAM untuk memenuhinya. Dari survey lokasi, survey penduduk untuk mengetahui berapa kebutuhan air yang diperlukan masyarakat sehingga dapat diketahui berapa kapasitas debit air yang harus dipenuhi.

Tujuan Penelitian ini untuk mengetahui jumlah kebutuhan air bersih rata-rata di IKK Karangbinangun. Untuk mengetahui perencanaan sistem jaringan air bersih yang baik dan memadahi untuk memenuhi kebutuhan air bersih bagi masyarakat.

\section{METODE PENELITIAN}

Penelitian ini akan dilakukan di kecamatan Karangbinangun kabupaten Lamongan, yang mana masyarakat kecamatan tersebut sangat membutuhkan sarana air bersih yang memadai, agar kebutuhan air bersih dapat tercukupi terutama pada saat musim kemarau. Untuk mendapatkan gambaran tentang rencana penyediaan sistem distribusi air bersih, perlu beberapa langkah yang harus dilakukan untuk memperoleh data-data sebagai acuan dalam perencanaan sistem jaringan air bersih. Untuk itu dalam tahap ini akan dijelaskan secara terperinci tahapan-tahapan yang akan dilakukan selama dalam kegiatan penelitihan.

Kebutuhan sistem jaringan air bersih di kecamatan karangbinangun sangat diperlakukan untuk mencukupi kebutuhan air bersih masyarakat kecamatan setempat.

\section{Rencana Penelitian}

Penelitian ini akan dilakukan di kecamatan Karangbinangun kabupaten Lamongan, yang mana masyarakat kecamatan tersebut sangat membutuhkan sarana air bersih yang memadai, agar kebutuhan air bersih dapat tercukupi terutama pada saat musim kemarau. Untuk mendapatkan gambaran tentang rencana penyediaan sistem distribusi air bersih, perlu beberapa langkah yang harus dilakukan untuk memperoleh data-data sebagai acuan dalam perencanaan sistem jaringan air bersih. Untuk itu dalam tahap ini akan dijelaskan secara terperinci tahapan-tahapan yang akan dilakukan selama dalam kegiatan penelitihan.

Kebutuhan sistem jaringan air bersih di kecamatan karangbinangun sangat diperlakukan untuk mencukupi kebutuhan air bersih masyarakat kecamatan setempat.

\section{Pengumpulan Data}

\section{a) Tahap Penelitian}

Rangkain penelitian ini terbagi menjadi empat tahap. Tahap pertama adalah tahap persiapan. Tahap kedua adalah tahap awal yang di dalamnya mencakup penelitian dan pengumpulan data. Tahap tahap ketiga yaitu tahap pengelolahan data. Tahap terakhir berisikan mengenai kesimpulan.

\section{b) Tahap Persiapan}

Tahap persiapan merupakan kegiatankagiatan pendahuluan yang dilakukan untuk memperjelas arah penelitian ini.

- Menetukan kebutuhan data.

- Mendata intansi yang dijadikan sumber.

- Survei lokasi untuk mendapatkan gambaran umum kondisi dilapangan

\section{c) Tahap Pengumpulan Data}

Data yang digunakan terdiri dari dua kelompok, yaitu :

a. Data primer

1. Survei lokasi

Survei dilakukan untuk memperoleh gambaran awal sebelum melakukan kegiatan pembangunan. Data yang diperolahbisa berupa foto lokasi, maupun data teknis yang berupa satuan dimensi.

2. Data survai penduduk

Data penduduk dapat berupa jumlah penduduk, data penggunaan air bersih dan data pemanfaat pengguna.

b. Data sekunder

1. Peta lokasi

Peta lokasi adalah gambar lokasi kegiatan, peta lokasi dapat diambil dari aplikasi Google Earth

2. Data jumlah penduduk

Untuk mendapat data jumlah penduduk dapat dilakukan dengan melihat hasil sensus penduduk, maupun dapat dilakukan secara langsung untuk mendapat data penduduk terbaru.

3. Data pengguna sarana

Data pengguna sarana dapat diperolah dari pihak pengelolah sarana air bersih. 


\section{d) Tahap Pengelolahan Data Analisa}

Setelah data yang diperlukan sudah diperoleh, selanjutnya data tersebut diolah menggunakan rumus empiris yang berkaitan, tanpa merubah keaslian data.

\section{e) TahapAkhir}

Merupakan tahapan terakhir dari suatu penelitian yang berisi mengenai hasil penelitian dalam bentuk solusi maupu penilaian.

Perhitungan hidrolis aliran pada jaringan ditribusi dilakukan berdasarkan besarnya aliran puncak pada akhir tahun perencanaan yang dipengaruhi oleh factor-faktor :

a. Jarak IPA dengan daerah pelayanan.

b. Tekanan yang tersedia pada IPA

c. Tekanan yang harus disediakan di setiap blok pelayanan.

d. Besar diameter pipa yang digunakan.

e. Kehilangan tekanan akibat friksi dalam pipa.

f. Kehilangan tekanan akibat perlengkapan pipa(fittings).

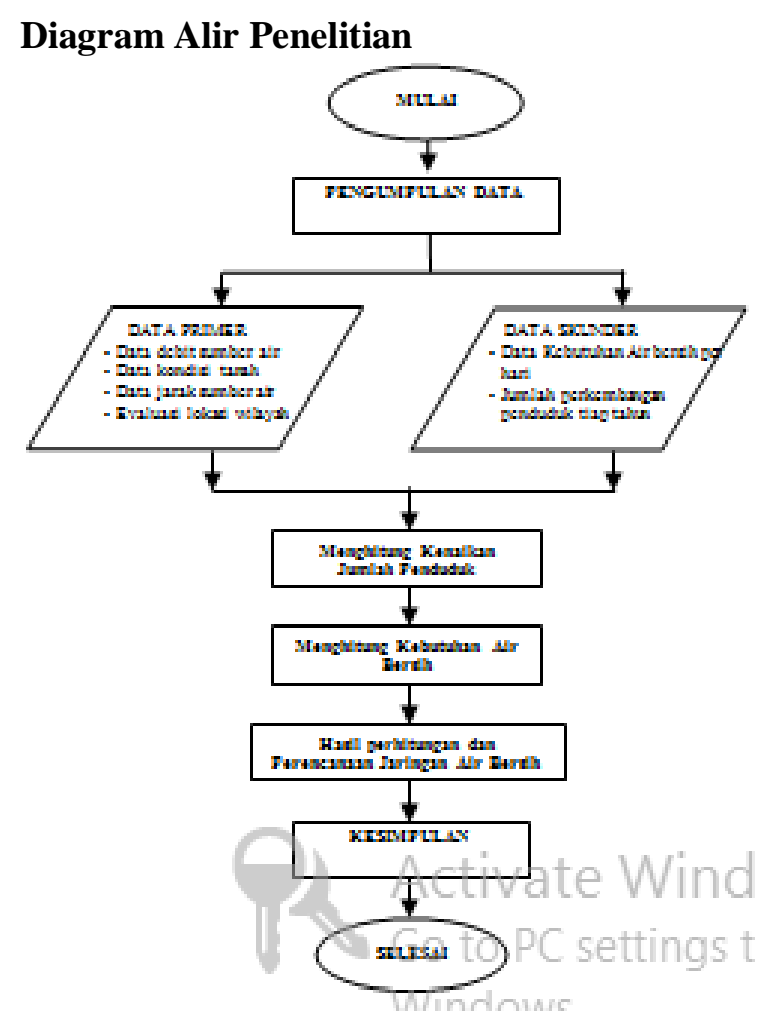

\section{HASIL DAN PEMBAHASAN}

Berdasarkan dari data Biro Pusat Statistik (BPS), diperoleh data penduduk eksisting untuk kecamatan terlayani yaitu Kecamatan Karangbinangun Kabupaten Lamongan.

Tabel 1 Data Jumlah Penduduk Tahun 2012 - 2016

\begin{tabular}{clccccc}
\hline NO & NAMA DESA & $\mathbf{2 0 1 2}$ & $\mathbf{2 0 1 3}$ & $\mathbf{2 0 1 4}$ & $\mathbf{2 0 1 5}$ & $\mathbf{2 0 1 6}$ \\
\hline 1 & Priyoso & 875 & 887 & 888 & 901 & 914 \\
\hline 2 & Kuro & 1598 & 1448 & 1458 & 1480 & 1501 \\
\hline 3 & Gawerejo & 1717 & 1691 & 1705 & 1730 & 1756 \\
\hline 4 & Windu & 1713 & 1649 & 1642 & 1666 & 1691 \\
\hline 5 & Karangbinangun & 2062 & 1991 & 1978 & 2007 & 2037 \\
\hline 6 & Sambopinggir & 2479 & 2407 & 2423 & 2459 & 2495 \\
\hline 7 & Blawi & 2706 & 2749 & 3342 & 3391 & 3441 \\
\hline 8 & Putatbangah & 1614 & 1591 & 1587 & 1610 & 1634 \\
\hline & JUMLAH & $\mathbf{1 4 7 6 4}$ & $\mathbf{1 4 4 1 3}$ & $\mathbf{1 5 0 2 3}$ & $\mathbf{1 5 2 4 4}$ & $\mathbf{1 5 4 6 9}$
\end{tabular}

Sumber: BPS KabupatenKarangbinangun,2012-2016.

Tabel 2 Data Penduduk Karangbinangun

\begin{tabular}{ccc}
\hline No. & Tahun & $\begin{array}{c}\text { Jumlah Penduduk } \\
(\text { Jiwa })\end{array}$ \\
\hline 1 & 2012 & 14764 \\
\hline 2 & 2013 & 14413 \\
\hline 3 & 2014 & 15023 \\
\hline 4 & 2015 & 15244 \\
\hline 5 & 2016 & 15469 \\
\hline Sumber $:$ BPS Kabupaten Karangbinangun, (2016).
\end{tabular}

Tabel 3 Presentase Perkembangan Penduduk

\begin{tabular}{cccc}
\hline No. & Tahun & Pertambahan & $\begin{array}{c}\text { Presentase } \\
(\%)\end{array}$ \\
\hline 1 & $2012-2013$ & -351 & $-2,37$ \\
\hline 2 & $2013-2014$ & 610 & 4,23 \\
\hline 3 & $2014-2015$ & 221 & 1,47 \\
\hline 4 & $2015-2016$ & 225 & 1,48 \\
\hline
\end{tabular}

Sumber : Hasil Perhitungan Pertumbuhan Penduduk Kecamatan Karangbinangun. 
Mencari nilai rata-rata dari $\mathrm{r}$

$$
\begin{aligned}
& r=\frac{-2,54+4,23+1,47+1,48}{4} \\
& r=1,16 \% \\
& r=0,0116
\end{aligned}
$$

Contoh menghitung jumlah penduduk tahun 2017 :

$$
\begin{aligned}
\text { P2017 } & =\mathrm{P} 2016(1+\mathrm{r})^{\mathrm{n}} \\
& =15469(1+0,0116)^{1} \\
& =15469(1,0116) \\
& =15648 \text { jiwa }
\end{aligned}
$$

Tabel 4 Prediksi Pertumbuhan Penduduk Pada Tahun 2017-2026

\begin{tabular}{ccc}
\hline No. & Tahun & Jumlah Penduduk \\
\hline 1. & 2017 & 15648 \\
\hline 2. & 2018 & 15836 \\
\hline 3. & 2019 & 16026 \\
\hline 4. & 2020 & 16218 \\
\hline 5. & 2021 & 16413 \\
\hline 6. & 2022 & 16609 \\
\hline 7. & 2023 & 16808 \\
\hline 8. & 2024 & 17010 \\
\hline 9. & 2025 & 17214 \\
\hline 10. & 2026 & 17420
\end{tabular}

Sumber : Hasil Perhitungan Prediksi Pertumbuhan Kecamatan Karangbinangun.

\section{Proyeksi Kebutuhan AirBersih}

Perhitungan kebutuhan air bersih untuk rumah tangga ada beberapa faktor yang harus diperhatikan :

1. Jangka waktu perencanaan.

2. Perkiraan jumlah penduduk dalam jangka waktu perencanaan.

3. Tingkat pertumbuhan penduduk per tahun. Jumlah kebutuhan air bersih sangat tergantung dengan jumlah penduduk, selain air digunakan sebagai kebutuhan dasar, air juga digunakan dalam industri peternakan desa dan lain sebagainya.

Tabel 5 Standar Kebutuhan Air Per Orang

\begin{tabular}{llc}
\hline No. & \multicolumn{1}{c}{ Kategori } & (1/orang/hari) \\
\hline $\mathbf{1}$ & $\begin{array}{l}\text { Metropolitan } \\
\text { penduduk 1 jutajiwa }\end{array}$ & 120 \\
$\mathbf{2}$ & $\begin{array}{l}\text { Kota besar penduduk } \\
0,5-1 \text { juta jiwa }\end{array}$ & 100 \\
$\mathbf{3}$ & $\begin{array}{l}\text { Kota sedang penduduk } \\
0,1-0,5 \text { jiwa }\end{array}$ & 90 \\
\hline
\end{tabular}

\begin{tabular}{lll}
\hline 4 & $\begin{array}{l}\text { Kota kecil penduduk } \\
20.000-100.000 \text { jiwa }\end{array}$ & 60 \\
\hline $\mathbf{5}$ & Semi urban penduduk & 45 \\
\hline
\end{tabular}

desa $3.000-20.000$

jiwa

Sumber : PU. Cipta Karya Kabupaten Lamongan.

(Dalam Prasetyo 2016).

Dari tabel di atas bisa diperhitungkan

\begin{tabular}{|c|c|c|}
\hline No & Keterangan & Unit Satuan \\
\hline 1. & $\begin{array}{l}\text { Tingkat Pelayanan: } \\
\text { a. Jumlah } \\
\text { jiwa/sambungan }\end{array}$ & $\begin{array}{l}5 \text { jiwa/unit } \\
\text { sambungan }\end{array}$ \\
\hline 2. & $\begin{array}{l}\text { Kebutuhan Air } \\
\text { Bersih } \\
\text { a. Domestik } \\
\text { b. Non domestik }\end{array}$ & $\begin{array}{l}60 \text { liter/orang/hari } \\
10(\%) \mathrm{x} \\
\text { kebutuhan } \\
\text { domestik }\end{array}$ \\
\hline 3. & $\begin{array}{l}\text { Kehilangan } \\
\text { air/kebocoran }\end{array}$ & $20(\%)$ \\
\hline 4. & Faktor maksimal & $\begin{array}{l}1,15 \times \text { kebutuhan } \\
\text { total }\end{array}$ \\
\hline 5. & Faktor jam puncak & $\begin{array}{l}2,3 \times \text { faktor hari } \\
\text { maksimal }\end{array}$ \\
\hline 6. & Target Pelayanan & $70 \%$ \\
\hline
\end{tabular}
kebutuhan air bersih untuk Kecamatan Karangbinangun dengan pemakaian kebutuhan air sebesar 60 liter/hari/orang.

Tabel 6 Kriteria Perencanaan

PelayananKebutuhan Air Bersih Kecamatan

Karangbinangun.

Sumber: PDAM Kabupaten Lamongan.

Tabel 7 Perencanaan Pelayanan Kebutuhan Air Bersih Kec. Karangbinangun.

\begin{tabular}{clcc}
\hline No & \multicolumn{1}{c}{ Uraian } & $\begin{array}{c}\text { Satua } \\
\mathrm{n}\end{array}$ & $\begin{array}{c}\text { Thn proyeksi } \\
2026\end{array}$ \\
\hline 1. & Jumlah Penduduk & Jiwa & 17420 \\
\hline 2. & $\begin{array}{l}\text { Presentase Pelayanan } \\
\text { Penduduk }\end{array}$ & $\%$ & 70 \\
\hline 3. & $\begin{array}{l}\text { Kebutuhan air } \\
\text { penduduk }\end{array}$ & $\mathrm{Lt} / \mathrm{hr}$ & 60 \\
\hline 4. & $\begin{array}{l}\text { Kebutuhan domestik }= \\
(1 \times 2 \times 3)\end{array}$ & $\mathrm{Lt} / \mathrm{hr}$ & 731.640 \\
\hline 5. & $\begin{array}{l}\text { Kebutuhan non } \\
\text { domestik }=(10 \% \text { x } 4)\end{array}$ & $\mathrm{Lt} / \mathrm{hr}$ & 73.164 \\
\hline & $\begin{array}{l}\text { Kehilangan air akibat } \\
\text { kebocoran }= \\
(20 \%(4+5))\end{array}$ & $\mathrm{Lt} / \mathrm{hr}$ & $160.960,80$ \\
\hline 7. & $\begin{array}{l}\text { Total kebutuhan rata- } \\
\text { rata }=(4+5+6)\end{array}$ & $\mathrm{Lt} / \mathrm{hr}$ & $965.764,80$ \\
\hline 8. & $\begin{array}{l}\text { Faktor kebutuhan harian } \\
\text { maksimal = }(1,15 \times 7)\end{array}$ & $\mathrm{Lt} / \mathrm{hr}$ & $1.110 .629,52$ \\
\hline 9. & $\begin{array}{l}\text { Faktor kebutuhan jam } \\
\text { puncak = (1,3x8) }\end{array}$ & $\mathrm{Lt} / \mathrm{hr}$ & $1.443 .818,38$ \\
\hline $\begin{array}{l}\text { Sumber: Hasil Perhitungan Kebutuhan Air Kec. } \\
\text { Karangbinangun }\end{array}$ & &
\end{tabular}

\section{Diameter Pipa Distribusi \\ $\mathrm{Q}=\mathrm{A} \times \mathrm{V}$ \\ $\mathrm{A}=\mathrm{Q} / \mathrm{V}$}




$$
\begin{aligned}
\mathrm{A} & =0,02 / 1=0,02 \mathrm{~m}^{3} \\
\mathrm{~A} & =1 / 4 x \pi x D^{2} \\
\mathrm{~A} & =1 / 4 x^{22} / 7 x D^{2} \\
& =22 / 2 x^{2} \\
\mathrm{D} & =\sqrt{A x^{28} / 22} \\
& =\sqrt{0,02 x^{28} / 22} \\
& =0,160 \mathrm{~m}=160 \mathrm{~mm} \approx 150 \mathrm{~mm}
\end{aligned}
$$

Jadi diameter pipa yang digunakan dalam jaringan distribusi air bersih di IKK Karangbinangun $160 \mathrm{~mm} \approx 150 \mathrm{~mm}$.

\section{Mayor losses}

Kehilangan tekanan yang terjadi pada sepanjang pipa lurus. Ini dapat diketahui dengan perhitungan menggunakan Persamaan Hazen-Williams :

$$
\begin{aligned}
& H F=10,667 L \frac{Q^{1,85}}{C^{1,85} D^{4,87}} \\
& H F=10,667 L \frac{0,02^{1,85}}{120^{1,85} 0,15^{4,87}} \\
& H F=10,667 L \frac{0,00072}{7022,39 \times 9,71} \\
& H F=10,667 L \frac{0,00072}{0,68} \\
& H F=10,667 \times 1587 \times 0,0011 \\
& H F=18,6
\end{aligned}
$$

Adalah kehilangan tekanan yang terjadi pada tempat yang memungkinkan adanya perubahan karakteristik aliran, misalnya pada valve, belokan, sambungan. Hal ini diperkirakan 50\% dari Mayor Losses.

Minor Losses $=18,6 \times 50 \%=9,3 \mathrm{~m}$

Jadi kehilangan tekanan total $=18,6+9,3=$ $27.9 \mathrm{~m}$

Sehingga agar air bisa mencapai pipa paling ujung atau terjauh harus memerlukan menara air setinggi 27,9 $\mathrm{m}$ atau pompa dengan spefikasi $\mathrm{Q}=16,71 \mathrm{lt} / \mathrm{dt}$ dan Head sebear 27,9 $\mathrm{m}$ atau $30 \mathrm{~m}$.

\section{KESIMPULAN}

Dengan hasil penulisan Laporan Tugas Akhir yang berjudul "Perencanaan sistem Air Bersih IKK Karangbinangun". Pelaksanaan penelitian ini sangat bemanfaat bagi perencana struktur, bagi masyarakat pemukiman dan bagi pemerintah kota, selama berlangsungnya penelitian penulis banyak menemukan hal baru yang bisa dipelajari. Seperti masalah-masalah yang timbul, baik menyangkut masalah teknis maupun non teknis. Hal ini menjadi suatu pengalaman dan ilmu baru yang mungkin bermanfaat bagi penulis di lain hari.

Selama melakukan kegiatan penulisan Laporan Tugas Akhir maka penulis dapat mengambil beberapa kesimpulan sebagai berikut:

1. Prediksi jumlah penduduk Di Kecamatan Karangbinangun tahun 2026 adalah 17420. Dan dari hasil perhitungan perencanaan dapat diketahui pelayanan kebutuhan air bersih di Kecamatan Karangbinangun pada tahun proyeksi 2026 debit minimal yang dibutuhkan adalah 1.443.818,38 lt/hr atau $60.159,10 \mathrm{lt} / \mathrm{jm}=1.002,65 \mathrm{lt} / \mathrm{mnt}=16,71$ $\mathrm{lt} / \mathrm{dt}=0,02 \mathrm{~m} 3 / \mathrm{dt}$.

2. Dari hasil perhitungan diketahui diameter pipa $150 \mathrm{~mm}$, dan spefikasi pompa $\mathrm{Q}=$ 16,71 lt/dt dan Head sebear 27,9 $\mathrm{m}$ atau 30 $\mathrm{m}$, untuk perencanaan sistem penyedia air bersih IKK Karangbinangun.

\section{DAFTAR PUSTAKA}

,2013, Juklak Program Sanitasi Lingkungan ,PU CIPTA KARYA LAMONGAN

Cipta Karya Kab. Lamongan

Ilyas,2006. Pengembangan Jaringan Distribusi Air Bersih Kota Sidoarjo Proyeksi Tahun 2020. Universitas Islam Lamongan.

M.Sarkowo,1985. Penyediaan Air Bersih,Jilid 1 Dan 2. Teknik Penyehatan, Institut Teknologi Sepuluh Novembersurabaya.

Mu'adlom, Ahmad,2012. Perencanaan Sistem Distribusi Air Bersih Di Ikk Glagah Kabupaten Lamongantahun Proyeksi 2012-2022. Universitas Islam Lamongan Prasyo,Eky Tulus, 2016, Perencanaan Sistem Penyediaan Air Bersih Di Desa Lawanganagung Kecamatan Sugio Kecamatan Sugia Kabupaten Lamongan, Universitas Islam Lamongan.

Sukarti, 2016 Arsip Desa Sukoanyar, Balai Desa Sukoanyar

Supriono,2015, Perencanaan Sistem Distribusi Air Bersih Di Desa Kedungasri Kec. Kembangbahu Tahun Proyeksi 20152020. Universitas Islam Lamongan 